\title{
A custom built lathe designed for in operando high-energy $x$-ray studies at industrially relevant cutting parameters
}

Cite as: Rev. Sci. Instrum. 90, 103901 (2019); https://doi.org/10.1063/1.5091766

Submitted: 06 February 2019 . Accepted: 20 September 2019. Published Online: 04 October 2019

L. Rogström (D), Y. H. Chen (D), M. P. Johansson Jõesaar (D), J. Eriksson, M. Fallqvist, J. M. Andersson, N. Schell, M. Odén (D), and J. Birch (D)

\section{ARTICLES YOU MAY BE INTERESTED IN}

The effect of particle shape in particle detection using inductive sensors

Review of Scientific Instruments 90, 105002 (2019); https://doi.org/10.1063/1.5099300

Dual-color near-field imaging by means of thin-film plasmonic waveguide with precise beam control of multiple wavelengths

Review of Scientific Instruments 90, 103701 (2019); https://doi.org/10.1063/1.5099505

A testing system for studying the effect of strain on thermal conductivity of thin films based on 3- $\omega$ technique

Review of Scientific Instruments 90, 104902 (2019); https://doi.org/10.1063/1.5095824

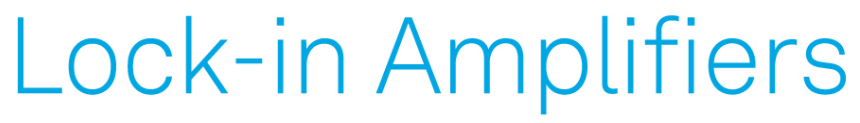

... and more, from DC to $600 \mathrm{MHz}$ Watch 


\title{
A custom built lathe designed for in operando high-energy $x$-ray studies at industrially relevant cutting parameters
}

Cite as: Rev. Sci. Instrum. 90, 103901 (2019); doi: 10.1063/1.5091766

Submitted: 6 February 2019 - Accepted: 20 September 2019 •

Published Online: 4 October 2019

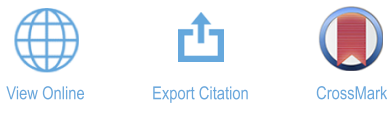

L. Rogström, ${ }^{1}$ (D) Y. H. Chen, ${ }^{1}$ (D) M. P. Johansson Jõesaar, ${ }^{1,2}$ (D) J. Eriksson, ${ }^{2}$ M. Fallqvist, ${ }^{2}$ J. M. Andersson, ${ }^{2}$

N. Schell, ${ }^{3}$ M. Odén, ${ }^{1}$ (D) and J. Birch ${ }^{4}$ (D)

\section{AFFILIATIONS}

${ }^{1}$ Nanostructured Materials, Department of Physics, Chemistry and Biology (IFM), Linköping University, 58183 Linköping, Sweden

${ }^{2}$ Seco Tools AB, 73782 Fagersta, Sweden

${ }^{3}$ Helmholtz-Zentrum Geesthacht (HZG), Max-Planck Str. 1, 21502 Geesthacht, Germany

4Thin Film Physics, Department of Physics, Chemistry and Biology (IFM), Linköping University, 58183 Linköping, Sweden

\begin{abstract}
We present a custom built lathe designed for in operando high-energy x-ray scattering studies of the tool-chip and tool-workpiece contact zones during operation. The lathe operates at industrially relevant cutting parameters, i.e., at cutting speeds $\leq 400 \mathrm{~m} / \mathrm{min}$ and feeds $\leq 0.3 \mathrm{~mm} / \mathrm{rev}$. By turning tests in carbon steel, performed at the high-energy material science beamline P07 at Petra III, DESY, Hamburg, we observe compressive strains in $\mathrm{TiNbAlN}$ and $\mathrm{Al}_{2} \mathrm{O}_{3} / \mathrm{Ti}(\mathrm{C}, \mathrm{N})$ coatings on the tool flank face during machining. It is demonstrated that by the right choice of substrate and coating materials, diffraction patterns can be recorded and evaluated in operando, both from the tool-workpiece and tool-chip contacts, i.e., from the contact zones between the tool and the workpiece material on the tool flank and rake faces, respectively. We also observe that a worn tool results in higher temperature in the tool-chip contact zone compared to a new tool.
\end{abstract}

Published under license by AIP Publishing. https://doi.org/10.1063/1.5091766

\section{INTRODUCTION}

Metal machining is one of the most important processes in manufacturing industries. Ensuring high precision machining and high production rates requires high performance cutting tools. The tool inserts are exposed to demanding conditions including high temperature and pressure in addition to abrasive wear from hard particles in the workpiece material. These conditions place high demands on both the tool material and its design. Optimizing the tools requires in-depth knowledge of both the conditions the tool experiences during machining and how the tool materials behave under these conditions.

Tool inserts are commonly coated by a thin $(1-20 \mu \mathrm{m})$, hard coating, which dramatically improves the wear resistance of the tool. Knowledge of the temperature and stress state in the coating is of high importance since this affects the phase stability and mechanical properties of the coating. A very well-known example of a coating material is TiAlN, which age hardens as a result of spinodal decomposition, ${ }^{2,3}$ and this behavior is affected by temperature and stress. ${ }^{1,4,5}$ Thus, the understanding of the coating properties during cutting requires local analysis of the coating in the cutting zone, which size is in the order of $1 \mathrm{~mm}^{2}$ and within which both temperature and pressure vary dramatically.

Today, the knowledge of the machining process is largely based on modeling of the stress and temperature distribution ${ }^{6-9}$ and studies of worn tools ${ }^{10,11}$ and the machined surfaces. ${ }^{12,13}$ A few measurements of tool temperature and stresses can be found. ${ }^{1,14,15}$ Direct observation of conditions and changes in the tool through, for example, in operando experiments is lacking. This can be understood by the lack of line-of-sight of the contact zone between the tool and the workpiece material.

Here, we present a custom-built lathe, designed to allow for $\mathrm{x}$-ray scattering studies of the tool during longitudinal turning, using industrial scale cutting parameters. The design enables realtime studies of the tool (substrate and coating) and the chip during machining. High-energy $x$-rays can penetrate both substrate and 
workpiece material and thus provide access to the contact zone. A two-dimensional detector can record the full $\mathrm{x}$-ray diffraction pattern within the order of seconds, enabling time-resolved studies of the evolution of phase content and states of strain and stress. The size of the synchrotron high-energy $\mathrm{x}$-ray beams can be controlled by slits or by focusing optics to beam sizes in the order of $10 \times 10 \mu \mathrm{m}^{2}$, thus allowing specific areas of interest to be selected for analysis. High-energy $\mathrm{x}$-ray scattering has previously been used as a valuable tool for investigating strains and stresses in ceramic tools during both thermomechanical loads and in friction testing. ${ }^{16,17}$ It has also been used to study the chip formation and the stress state in operando during cutting and the stress state of the chip during cutting. ${ }^{18-20}$ In addition, high-energy $\mathrm{x}$-ray scattering has been shown to be a useful tool for studying phase transformations and strains in hard coatings. ${ }^{5,21-24}$

We present here the first in operando results from an industrially relevant turning operation with a coated tool, recorded at the high-energy materials science beamline P07 at Petra III, using a two-dimensional detector and an $\mathrm{x}$-ray energy of $\sim 80 \mathrm{keV}$. PVD grown TiNbAlN and CVD grown $\mathrm{Al}_{2} \mathrm{O}_{3} / \mathrm{Ti}(\mathrm{C}, \mathrm{N})$ coated tools were used to machine $\mathrm{C} 45 \mathrm{E}$ carbon steel at a cutting speed of 230 or $320 \mathrm{~m} / \mathrm{min}$. The results reveal that there is a compressive stress on the tool flank side during machining and that the stress increases as the tool becomes worn. A worn tool also results in an increased temperature of the chip.

\section{LATHE DESIGN}

The lathe is designed to access the tool from the backside such that the $\mathrm{x}$-ray beam travels through the tool and the chip before continuing to the detector. Figure 1 (a) shows a schematic top-view of the $\mathrm{x}$-ray beam with respect to the tool and the workpiece. Figure 1(b) shows a photo of the tool in operation, as viewed from the detector, and Figs. 1(c) and 1(d) show an example of the two-dimensional raw data. As observed in Fig. 1(c), there are shadows, from the workpiece to the left and from the tool holder in the lower right corner, as illustrated in Fig. 1(d). The shadows arise from blocking of the background radiation that originates from scattering of the $\mathrm{x}$-ray beam in air. In the diffractogram, the diffraction signal from both the PCBN substrate and the steel work piece is observed. The strong Fe-signal above and below the shadow from the tool is the diffraction signal from loose chips behind of or in front of the tool [see Fig. 1(b)].

Figure 2 shows a drawing of the lathe. A steel frame with a physical size of $400 \times 400 \times 840 \mathrm{~mm}^{3}$ contains the workpiece, the tool holder, and the parts for vertical, horizontal, and rotational motion
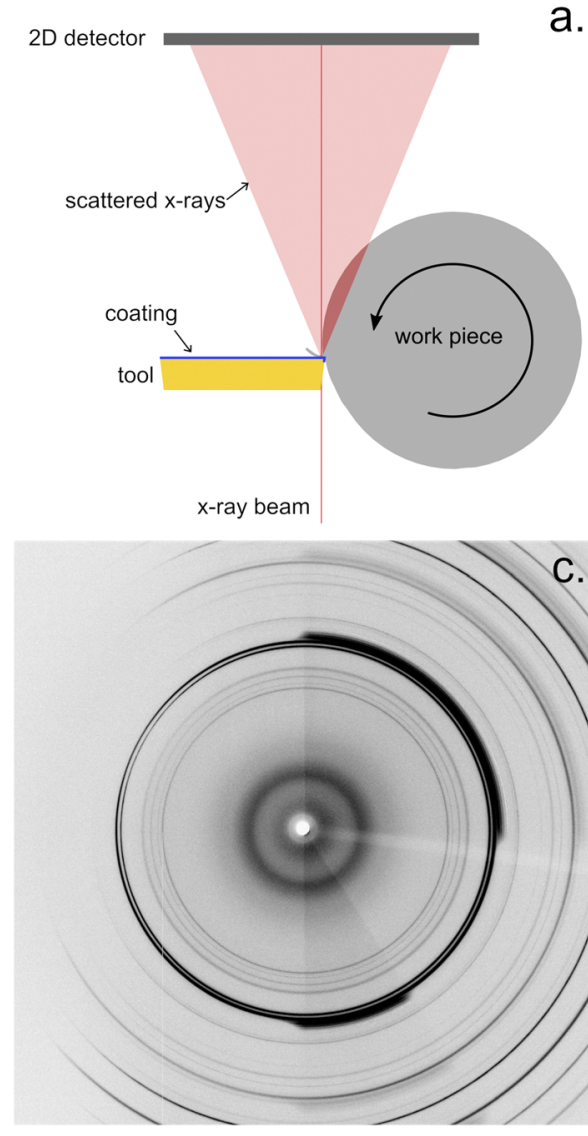

c. a.
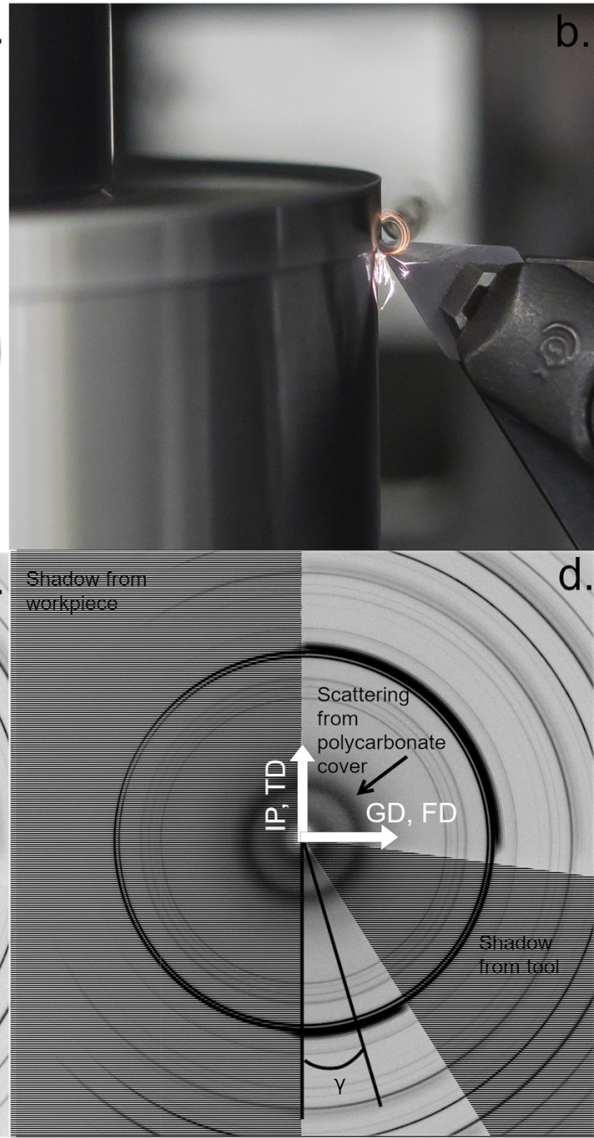

FIG. 1. (a) Schematic top-view of the tool and workpiece; (b) is a photo of the tool and workpiece; (c) shows a raw image from the 2D-detector; and in (d) the features in (c) are marked. In (d), also the chip flow direction (FD), the transverse direction (TD), the coating growth direction (GD), and in-plane direction (IP) on the flank face are indicated with the azimuthal angle $\gamma$. 
a
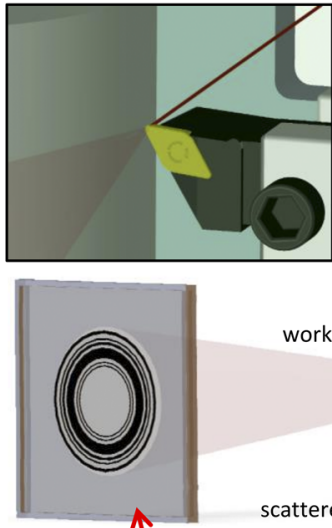

$2 \mathrm{D}$ detector

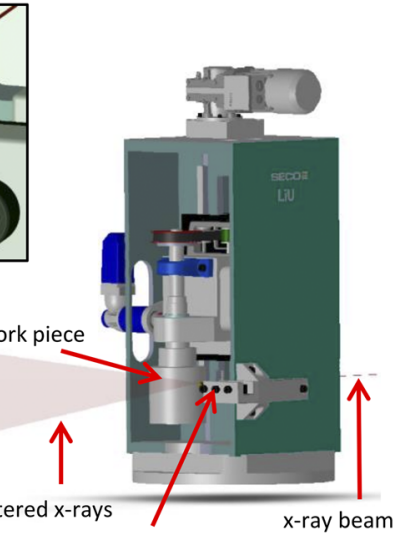

tool holder

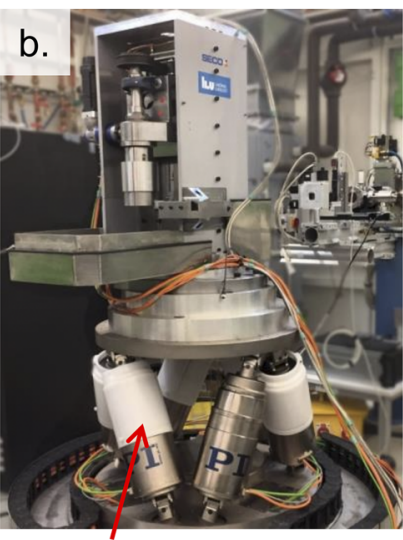

heavy-load hexapod
FIG. 2. (a) Drawings of the lathe, illustrating the entrance and exit of the $x$-ray beam. The top left insert shows a detail of the $x$-ray path through the tool. (b) shows a photo of the rig placed at the heavy-load hexapod at beamline P07, Petra III. of the workpiece. The total weight of the machine is $300 \mathrm{~kg}$ including the workpiece. The frame of the lathe has been designed to ensure stability and at the same time allow for entrance of the $\mathrm{x}$-ray beam as well as exit of the scattered $\mathrm{x}$-rays. The $\mathrm{x}$-ray beam enters through an opening at the backside, and the scattered $\mathrm{x}$-rays exit at the open front side.

The workpiece is mounted on a vertical spindle. The workpiece is free in one end and has been shaped to minimize vibrations by always having the moment of inertia below the tool contact point. The rotation of the spindle is controlled by a motor positioned at the backside of the lathe, and the maximum rotation speed is $800 \mathrm{rpm}$. The maximum diameter of the workpiece is $160 \mathrm{~mm}$, resulting in a maximum cutting speed of $400 \mathrm{~m} / \mathrm{min}$. A motor placed at the top of the frame controls the vertical movement of the spindle and gives a maximum feed rate of $0.3 \mathrm{~mm} /$ revolution.

The motion of the workpiece is controlled remotely by a wired controller that can be placed in the control hutch at the beamline. Thus, the cutting operation can be both started and interrupted and changes in the cutting parameters can be made from the control hutch. When one full length of the workpiece has been machined, i.e., when the vertical movement of the workpiece reaches the bottom position, the workpiece is automatically moved out of contact of the tool and moved back to its top position from where a new cycle can be started. Thus, the contact time is determined by the length of the workpiece and the cutting parameters and is typically between 30 and $60 \mathrm{~s}$.

The tool is mounted on a stationary tool holder that is stiff in all directions and can easily be exchanged to other cutting tool holders. This makes it possible to use different geometries and cutting angles without any unwanted movement of the lathe. The entire construction is designed to be stiff and to minimize vibrations.

Polycarbonate covers on the front and backside of the lathe ensure that chips do not leave the setup. The $\mathrm{x}$-ray beam enters the lathe through a hole in the cover, while the diffracted $\mathrm{x}$-rays leave the setup through the cover. The cover does not disturb the scattered $\mathrm{X}$-rays, thanks to its $\mathrm{x}$-ray transparency.

During the in operando experiments reported here, the lathe was positioned at the heavy load hexapod at beamline P07, Petra III, as shown in Fig. 2(b). Two adapter plates below the lathe ensure that the hexapod is close to its lowest position to minimize vibrations and further correct the center of mass to ensure maximum stability of the hexapod. The lathe can be transferred to other sample stages by changing the adapter plate.

\section{IN OPERANDO TURNING TESTS AT P07, PETRA III}

\section{A. Experimental details}

Two initial tests were performed at beamline P07, Petra III, one aimed at studying the coating on the flank side of the tool and one targeting the hottest part of the chip. Figure 3(a) shows an overview of the experimental setup [a close-up of Fig. 1(a)] and the beam position onto the tool for the two experiments. Beam position A was used for studies of the coating on the flank face of the tool, and beam position B was used to study the chip.

For studies of the flank face of the tool, coated WC-Co tools (DCMT11T304-F1) were used. Since the absorption of X-rays is large in WC-Co, the choice of this substrate material ensures that only the diffraction signal from the flank face, close to the nose of the tool, reaches the detector. Two types of coatings were used, PVD grown TiNbAlN and CVD grown $\mathrm{Al}_{2} \mathrm{O}_{3} / \mathrm{Ti}(\mathrm{C}, \mathrm{N})$. $\mathrm{Ti}_{0.42} \mathrm{Nb}_{0.17} \mathrm{Al}_{0.41} \mathrm{~N}$ coatings were grown by cathodic arc evaporation to a thickness of 3 $\mu \mathrm{m}$ using Ti-Nb-Al alloy cathodes in a $4.5 \mathrm{~Pa} \mathrm{~N}$ atmosphere similar to what is described by Tasnádi et al. ${ }^{25}$. Before deposition, the substrates were sputter cleaned with Ar ions. The growth temperature was $500{ }^{\circ} \mathrm{C}$, and a negative substrate bias of $30 \mathrm{~V}$ was used. The CVD $\operatorname{Ti}(\mathrm{C}, \mathrm{N})$ layers $(7 \mu \mathrm{m}$ thickness) were deposited at a temperature of $860^{\circ} \mathrm{C}$ from a gas mixture of $\mathrm{CH}_{3} \mathrm{CN}-\mathrm{TiCl}_{4}-\mathrm{H}_{2}-\mathrm{N}_{2}$, and the $\alpha-\mathrm{Al}_{2} \mathrm{O}_{3}$ layers [5 $\mu \mathrm{m}$ thickness with (0001) texture] were subsequently deposited from the $\mathrm{AlCl}_{3}-\mathrm{CO}_{2}-\mathrm{CO}-\mathrm{H}_{2} \mathrm{~S}-\mathrm{H}_{2}$ system at $1000{ }^{\circ} \mathrm{C}$.

For studies of the chip, PCBN tools (DNMN110304) were used due to the low absorption of $\mathrm{x}$-rays by PCBN. The tools were coated by a CVD grown $\mathrm{Al}_{2} \mathrm{O}_{3} / \mathrm{Ti}(\mathrm{C}, \mathrm{N})$ using the growth conditions described above.

Turning experiments were performed at two different cutting speeds, $230 \mathrm{~m} / \mathrm{min}$ and $320 \mathrm{~m} / \mathrm{min}$. The feed was set to $0.15 \mathrm{~mm} / \mathrm{rev}$, and the depth of cut was $0.2 \mathrm{~mm}$ for all runs. The workpiece material 
a.

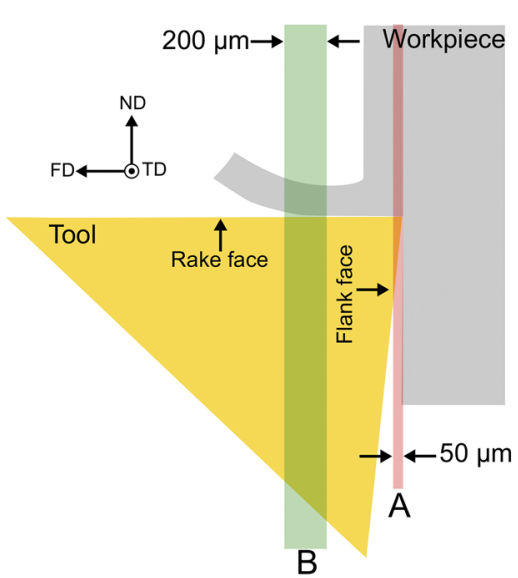

b.

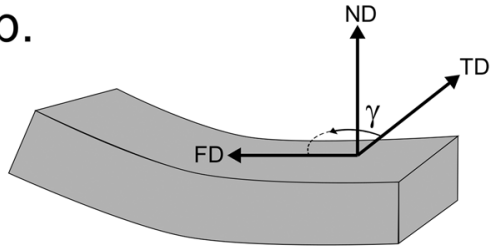

C.

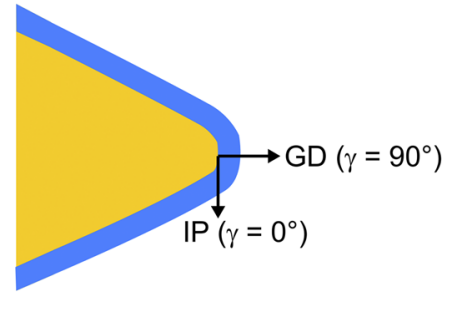

FIG. 3. (a) Schematic top-view of the tool and workpiece showing the beam positions (A and $B$ ) for the two experiments; (b) side view of the chip defining the normal direction (ND), parallel to the x-ray beam, the chip flow direction (FD), and the transverse direction (TD); (c) view along the beam of the nose of the tool defining the coating growth direction $(G D)$ and in-plane direction (IP), both perpendicular to the beam. was $\mathrm{C} 45 \mathrm{E}$ carbon engineering steel. Cutting one length of the workpiece takes approximately $50 \mathrm{~s}$ for the lower cutting speed and $30 \mathrm{~s}$ for the higher cutting speed. For each insert, at least three lengths were cut.

The experiments were performed using an x-ray energy of $78-79.5 \mathrm{keV}$ (wavelength of $0.159-0.156 \AA$ ). The size of the beam was defined by slits to $200 \times 50 \mu \mathrm{m}$ for beam position $\mathrm{A}$ and $200 \times 200 \mu \mathrm{m}$ for beam position $\mathrm{B}$. The diffracted $\mathrm{x}$-rays were detected by using a two-dimensional Perkin-Elmer detector with a pixel size of $200 \times 200 \mu \mathrm{m}^{2}$ and $2048 \times 2048$ pixels, positioned approximately $3.3 \mathrm{~m}$ from the sample. To maximize the resolution, the detector was positioned such that only the bottom right quadrant of Fig. 1(d) was recorded. The exact detector position was determined by measurements of a NIST $\mathrm{LaB}_{6}$ standard sample placed at the position of the tool. Each image consisted of 40-60 summed $1 \mathrm{~s}$ long exposures; thus, one image was recorded per length of cut.

The two-dimensional data were integrated in $5^{\circ}$ wide $\gamma$-sectors, and the resulting one-dimensional data were analyzed by fitting of Gaussian curves to the diffraction signal from the coating, substrate, and chip to extract the peak position and peak width (FWHM). Figures 1(d) and 3(c) show the definition of the in-plane (IP) and growth direction (GD) and the azimuthal angle $\gamma$. The plane spacing (d) was determined from the peak position using Bragg's law, and the $d$-values were subsequently plotted as a function of $\sin ^{2} \psi$ and a linear function was fitted to the data. The $\gamma$-angles were transformed to $\psi$ through the following relation:

$$
\psi(0 \leq \gamma \leq \pi / 2)=\pi / 2-\gamma-\theta \cos \gamma,
$$

where $\theta$ is the scattering angle. ${ }^{26}$ The strain in the in-plane direction was calculated through

$$
\varepsilon_{I P}=\frac{d_{90^{\circ}}-d_{0}}{d_{0}}
$$

where $d_{90^{\circ}}$ is the $\mathrm{d}$-value at $\psi=90^{\circ}$ extracted from the linear fit and $d_{0}$ is the strain-free plane spacing. The strain-free plane spacing used to calculate strain and thermal expansion was obtained at the invariant tilt angle $\psi^{*}$, given by

$$
\sin ^{2} \psi^{*}=\frac{2 v}{1+v} .
$$

For TiAlNbN, the 220 diffraction signal and $v=0.38$ were used; ${ }^{27}$ for WC, the 101 or 100 diffraction signal and $\nu=0.185$ were used; ${ }^{28}$ for $\mathrm{Al}_{2} \mathrm{O}_{3}$, the 104 diffraction signal and $v=0.23$ were used; ${ }^{29}$ and for TiCN, the 200 diffraction signal and the Poisson ratio for TiN ( $v$ $=0.22$ ) were used. ${ }^{30}$ The approximation $d_{0}=d^{*}$ excludes any hydrostatic component to the strain. To determine the full stress state, data must be recorded for at least three different $\phi$-orientations, while the used geometry limits the measurement to one $\phi$-angle.

For the chip, only data in the range $\gamma=\left[30^{\circ}: 90^{\circ}\right]$ where $\gamma=90^{\circ}$ corresponds to the chip flow direction (FD) and $\gamma=0^{\circ}$ corresponds to the transverse direction (TD), see the definition of angles in Figs. 1(d) and 3(b), were analyzed. Between $\gamma=0^{\circ}$ and $\gamma=30^{\circ}$, the diffraction signal from loose chips interfere with the desired diffraction signal (from the tool-chip contact zone), while at $30^{\circ}<\gamma<90^{\circ}$, the tool holder blocks diffraction signal from the loose chips [see Figs. 1(c) and 1(d)].

The temperature of the coating, substrate, and chip was estimated by the thermal expansion,

$$
d_{T}=d_{R T}(1+\alpha \Delta T) .
$$

Here, $d_{T}$ is the measured unstrained plane spacing at elevated temperature $\left(d_{T}=d^{*}\right), d_{R T}$ is the plane spacing at room temperature $\left(25^{\circ} \mathrm{C}\right), \alpha$ is the thermal expansion (see Table I, Sec. III B 2), and $\Delta T$ is the difference in temperature compared to room temperature.

Worn inserts were studied by scanning electron microscopy (SEM, Leo 1550 Gemini) using 5-15 kV acceleration voltage and the secondary electron (SE) detector.

\section{B. Results and discussion}

\section{Contact between tool and workpiece}

For studies of both the coating and of the chip formation, relevant contact conditions are crucial. A smooth and continuous wear of the cutting tool is needed to secure high enough local temperature and pressure to be of interest to analyze. In addition, the coating adhesion to the substrate is important to maintain the coating in the wear zone during the entire cutting test. 
TABLE I. Temperature extracted from the thermal expansion.

\begin{tabular}{|c|c|c|c|c|c|}
\hline & Cutting & $\begin{array}{c}\mathrm{T}(\text { sub }) \\
\left({ }^{\circ} \mathrm{C}\right)\end{array}$ & $\begin{array}{c}\mathrm{T}(\mathrm{TiNbAlN}) \\
\left({ }^{\circ} \mathrm{C}\right)\end{array}$ & $\underset{{ }^{\circ} \mathrm{C}}{\mathrm{T}}\left(\mathrm{Al}_{2} \mathrm{O}_{3}\right)$ & $\stackrel{\mathrm{T}(\mathrm{TiCN})}{{ }^{\circ} \mathrm{C}}$ \\
\hline CTE & $(\mathrm{m} / \mathrm{min})$ & $5.0 \times 10^{-6} \mathrm{~K}^{-1 a}$ & $1.0 \times 10^{-5} \mathrm{~K}^{-1 \mathrm{~b}}$ & $7.5 \times 10^{-6} \mathrm{~K}^{-1 c}$ & $9.4 \times 10^{-6} \mathrm{~K}^{-1 \mathrm{~d}}$ \\
\hline TiNbAlN/ & 230 & 450 & 330 & $\ldots$ & $\ldots$ \\
\hline WC-Co & 320 & 490 & 340 & $\ldots$ & $\ldots$ \\
\hline $\mathrm{Al}_{2} \mathrm{O}_{3}-\mathrm{TiCN} /$ & 230 & 440 & $\cdots$ & 410 & 340 \\
\hline WC-Co & 320 & 460 & $\cdots$ & 420 & 360 \\
\hline
\end{tabular}

${ }^{\text {a }}$ From Ref. 32.

${ }^{\mathrm{b}}$ From Ref. 33 .

${ }^{\mathrm{c}}$ From Ref. 34 at $400{ }^{\circ} \mathrm{C}$

${ }^{\mathrm{d}}$ Assuming the same value as for TiN, Ref. 28.

Figure 4 shows SEM micrographs of worn, TiAlNbN coated tools used during the tests. For both PCBN and WC-Co tools, these micrographs reveal good contact between the tool and the workpiece. The SEM studies also show that there is still coating present at both the rake face and the flank face of the tool after the measurements.

\section{Stress and temperature on the tool edge}

For measurements on the flank side of the tool, coated WC-Co inserts were used to limit the diffraction signal to the very edge of the tool insert. Figure 5 shows the 2D diffraction patterns from the
TiAlNbN coated tool, before use (a) and during the first length of cut (b). Before use, the diffraction signal from the very edge of the WC-Co substrate as well as from the TiAlNbN coating is observed. During machining, the additional diffraction signal from the workpiece material $(\mathrm{Fe})$ appears. Figure 6 shows one-dimensional lineouts integrated in $30^{\circ}$-wide $\gamma$-sectors from the coated tools $\left(\gamma=\left[30^{\circ}: 60^{\circ}\right]\right)$. The position of the diffraction peaks from the coatings shifts during the use of the tool, mainly due to thermal expansion as discussed below. The increased peak widths during machining are assigned to inhomogeneous temperature and strain within the measuring volume.
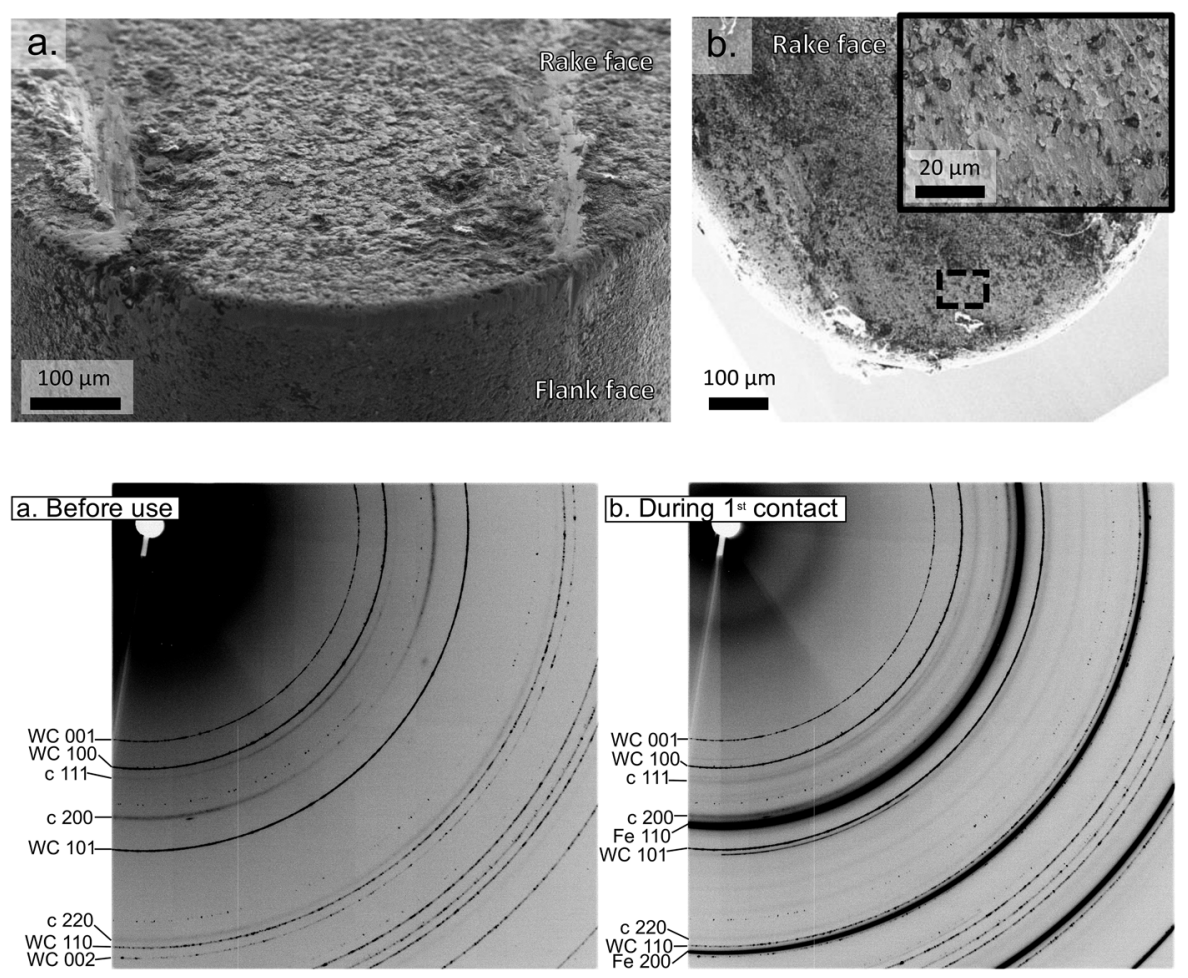

FIG. 4. SEM secondary electron micrographs of the worn TiNbAIN coated tools: (a) a coated PCBN tool and (b) a coated WC-Co tool. The inset in (b) shows a higher magnification micrograph from the region in the dashed box. 
a. TiNbAIN 220
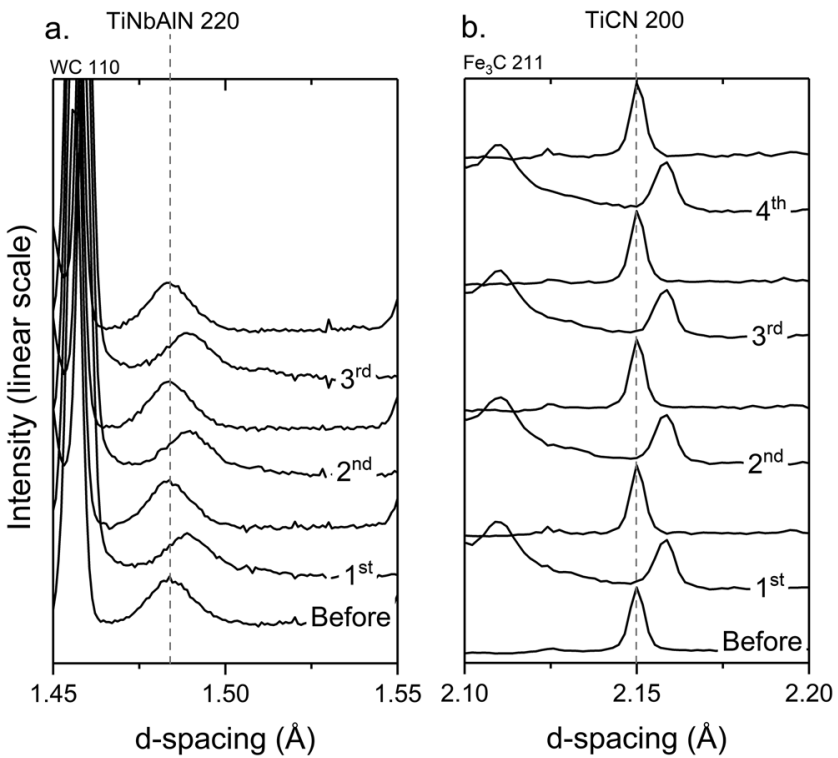

For both samples, the intensity of the coating peaks, the peak position, and the peak width are similar before use and after machining. This shows that there are no large changes in the measured sample volume or grain sizes and indicates that there is little reduction in coating thickness due to wear during the experiment.

Figure 7 shows the unstrained plane spacing, $\mathrm{d}^{*}$, extracted from the measurements during use, and before and after use of the insert. During use, the lattice parameter increases due to thermal expansion. The temperature calculated from the thermal expansion

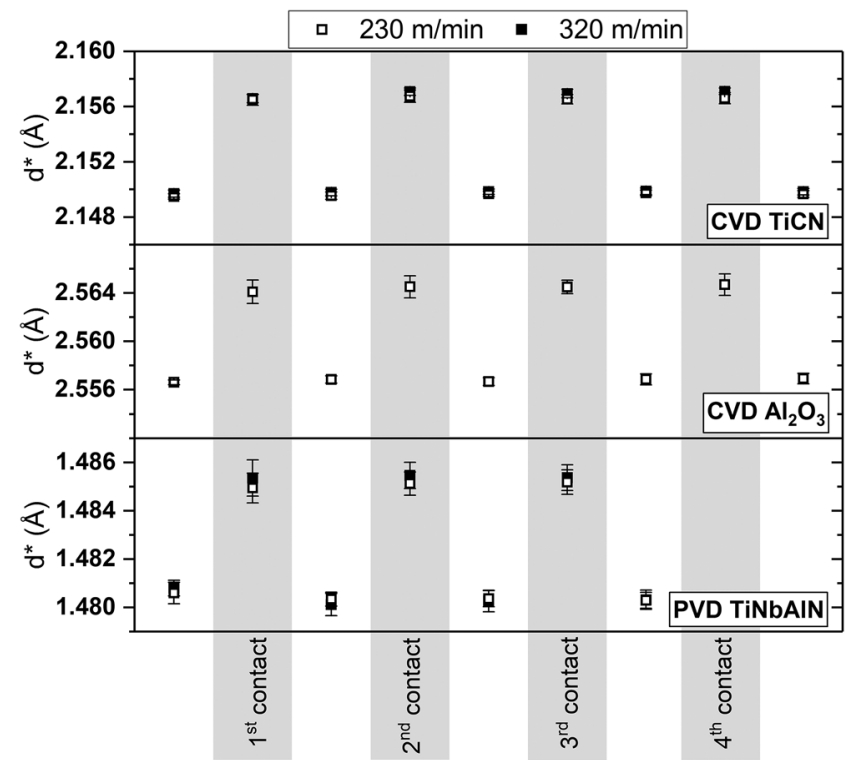

FIG. 7. The strain-free plane spacing of the TiAINbN and $\mathrm{Al}_{2} \mathrm{O}_{3} / \mathrm{TiCN}$ coatings before contact, during contact, and after each contact.
C. $\quad \mathrm{Al}_{2} \mathrm{O}_{3} 104$

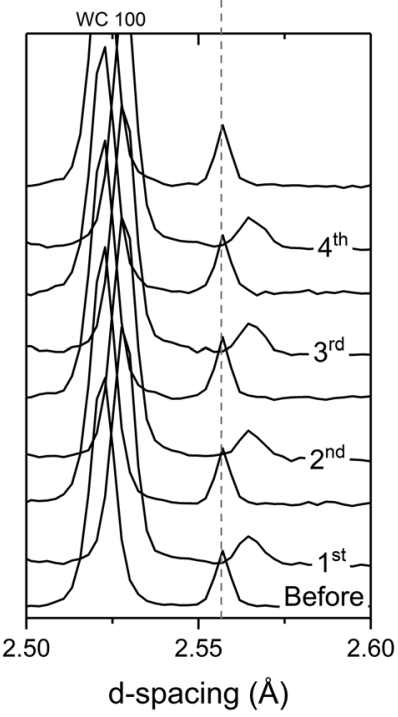

FIG. 6. Lineouts from the TiAINbN (a) and $\mathrm{Al}_{2} \mathrm{O}_{3} / \mathrm{TiCN}[(\mathrm{b})$ and $(\mathrm{c})]$ coated WC$\mathrm{Co}$ inserts before use, during machining (1st-4th contact), and after each contact. The coating peaks are indexed with dashed lines. is presented in Table I for all coatings as well as that of the substrate. The extracted temperature is similar for the coating materials and for the substrate and lies in the range of $330-490^{\circ} \mathrm{C}$. This is the average temperature in the irradiated volume. The broadening of diffraction peaks during machining (Fig. 6) suggests that the temperature varies within this volume; thus, the maximum temperature on the flank face is higher than this. The value of the coefficient of thermal expansion (CTE) gives an additional uncertainty in the determined temperature for both the substrate and the coatings. There are few reported values of the temperature of the flank face of the tool. Norrby et al. ${ }^{1}$ reported the temperature distribution on the tool. The measured temperature on the flank face is above $550^{\circ} \mathrm{C}$, but the steep gradient on the flank face makes it difficult to obtain the exact temperature. The lower temperature measured here probably has several origins such as the aforementioned temperature distribution within the measured volume and the difference in cutting parameters such as feed. For the PVD grown TiNbAlN coating, the small decrease in $\mathrm{d}^{*}$ between the as-deposited sample and after one length of cut is likely due to a change in the defect concentration as defect annihilation commonly occurs when the coating is exposed to high temperatures. ${ }^{31}$ This indicates that the temperature is higher than the deposition temperature $\left(500^{\circ} \mathrm{C}\right)$ in part of the measured coating volume.

Figure 8 shows the strain evolution in the coating during machining. In the as-deposited state, the PVD grown TiAlNbN coating exhibits a strain of $-0.092 \%$. In contrast, both the $\operatorname{Ti}(\mathrm{C}, \mathrm{N})$ phase and the $\mathrm{Al}_{2} \mathrm{O}_{3}$ phase of the CVD grown coating exhibit tensile strains of $0.078 \%$ and $0.074 \%$, respectively. During machining, the coating is exposed to a compressive stress resulting in larger compressive strains in the PVD coating and lower tensile strains in the CVD coating. The mean strain in the irradiated volume during machining at $230 \mathrm{~m} / \mathrm{min}$ is $-0.2228 \%$ for the PVD coating and $0.0484 \%$ for $\mathrm{Ti}(\mathrm{C}, \mathrm{N})$ and $-0.0026 \%$ for $\mathrm{Al}_{2} \mathrm{O}_{3}$. To calculate the expected triaxial stress of the coating during machining, accurate knowledge of the strain free plane spacing is required, in addition 


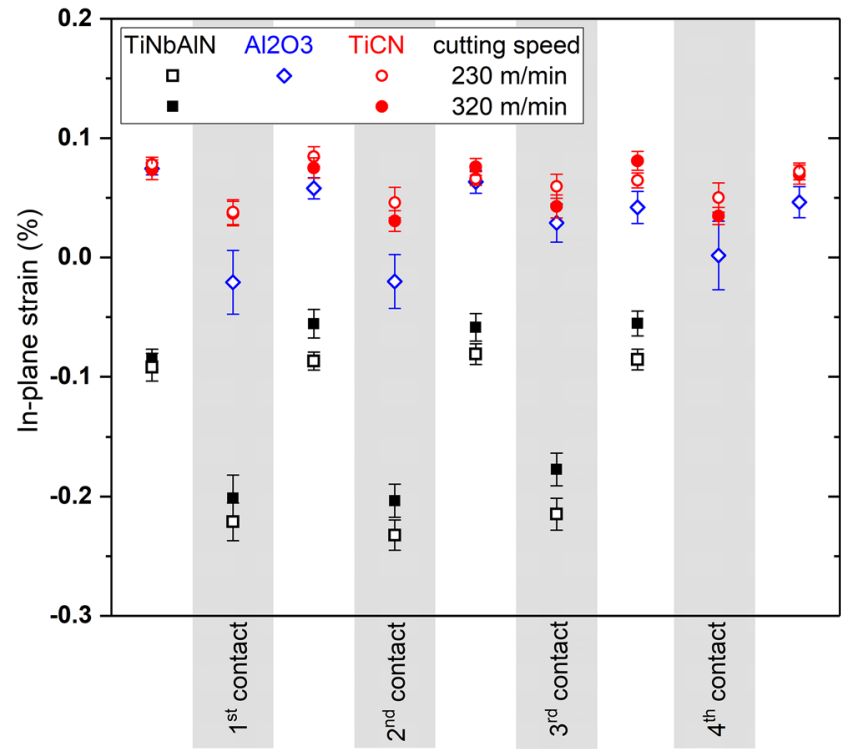

FIG. 8. In-plane strain of the TiAINbN and $\mathrm{Al}_{2} \mathrm{O}_{3} / \mathrm{TiCN}$ coatings before contact, during contact, and after contact.

to knowledge of the coating temperature and the elastic constants at elevated temperatures. The used measurement methodology when setting $\mathrm{d}_{0}=\mathrm{d}^{*}$ limits the information to deviatoric strains; thus, full stress determination is not possible. The largest scattering is seen in the data from the $\mathrm{Al}_{2} \mathrm{O}_{3}$ phase, which is related to the lower intensity of the diffraction peak of this phase for some $\gamma$-angles due to a strong texture of the coating.

For the PVD TiAlNbN coating, there is a small decrease in strain between the as-deposited coating and the coating after the first length of cut, indicating that relaxation or defect annihilation takes place during machining. Defect annihilation commonly takes place at temperatures above the deposition temperature, ${ }^{31}$ but annealing studies are normally performed for longer times compared to the less than $1 \mathrm{~min}$ high temperature exposure here. The decrease is larger for the higher cutting speed; thus, more relaxation takes place in the coating when increasing the cutting speed. This suggests that the temperature is higher for the higher cutting speed, despite the similar values obtained here (Table I).

The strain during machining is slightly smaller during the third length of cut compared to the first two contacts. This indicates that the stress on the tool changes as the surface and tool-workpiece contact conditions are changed due to wear. In the CVD coating, there is a smaller difference in strain between when the tool is in contact and after contact for the last two cut lengths for both the $\mathrm{Al}_{2} \mathrm{O}_{3}$ and the TiCN phases. This indicates that the stress onto the tool also changes for this tool due to modifications of the surface and thus a change in the contact between the tool and workpiece.

\section{Analysis of the chip}

For analysis of the chip, $\mathrm{x}$-ray transparent coated PCBN tools were used and the $\mathrm{x}$-ray beam was positioned at the hottest part of

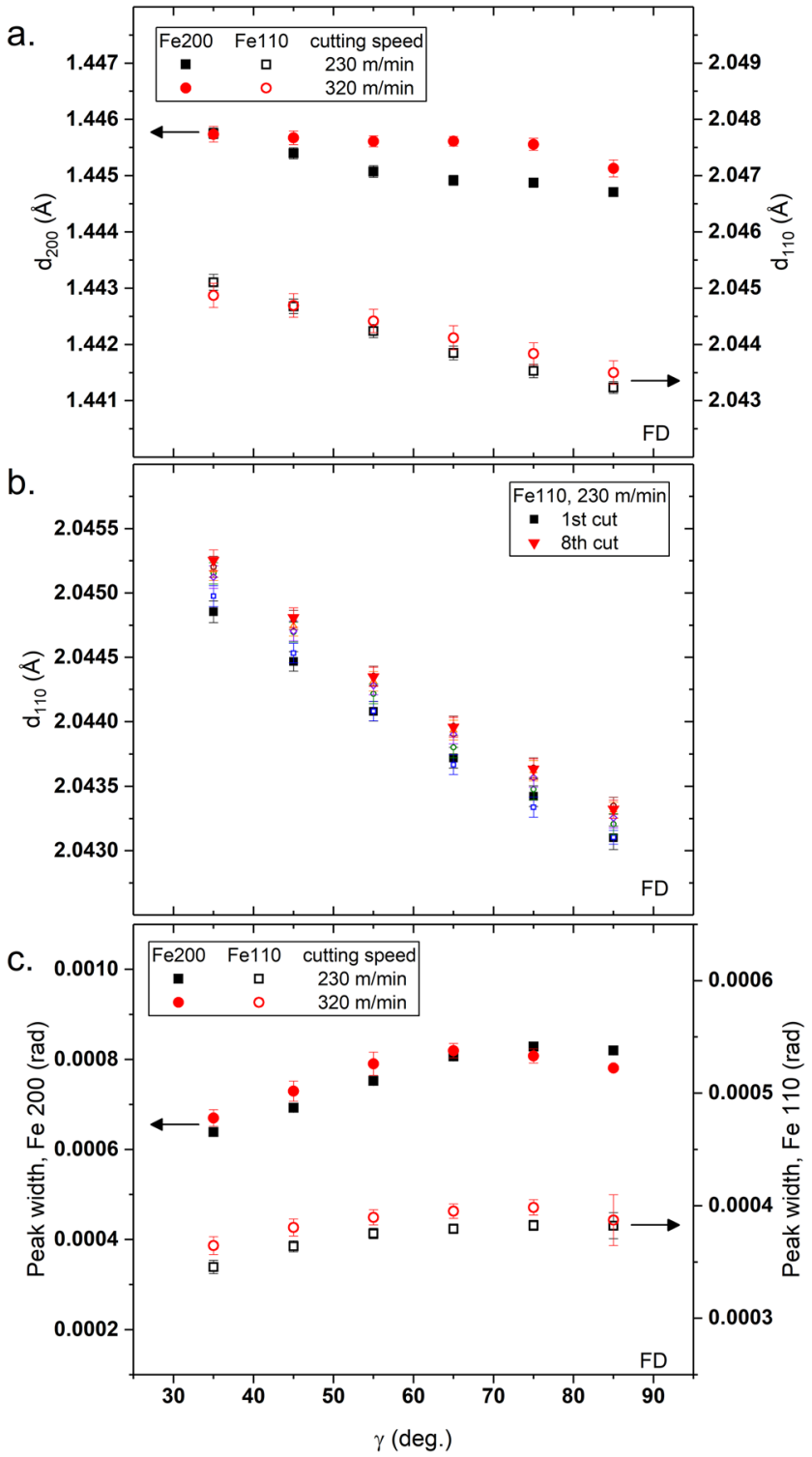

FIG. 9. (a) Plane spacing extracted from the two cutting speeds, (b) plane spacing for length 1-8 for $230 \mathrm{~m} / \mathrm{min}$, and (c) peak widths for the two cutting speeds. The data are shown as a function of angle to the chip flow direction (FD). In (b), the open symbols correspond to lengths 2-7 and the data from the 1 st and the 8th length are highlighted by filled symbols.

the chip [position B in Fig. 3(a)]. Figure 9(a) shows the d-spacing extracted from the $\mathrm{Fe} 200$ and $\mathrm{Fe} 110$ diffraction peaks during the two runs with different cutting speeds. The plane spacing of the Fe 110 peak is smallest in the flow direction (FD) and increases with decreasing $\gamma$. For the 200 diffraction peak, the trend is similar for the run at $230 \mathrm{~m} / \mathrm{min}$, while the behavior is slightly different for the run at $320 \mathrm{~m} / \mathrm{min}$. However, the smallest $d_{200}$ value is still found in the chip flow direction, which is likely related to compressive strain in 
this direction. The exact strain and stress of the chip cannot be determined due to the lack of data in the normal direction [ND, Fig. 3(b)] with the current experimental setup. Uhlmann et al. determined the stress state of the chip during low-speed orthogonal cutting. ${ }^{18}$ They found a larger compressive stress in the transverse direction compared to the chip flow direction, thus contrary to the results presented in this work. Uhlmann et al. could not evaluate the stress in the transverse direction [TD, Fig. 3(b)] directly in their experimental setup, while finite element method (FEM) simulations revealed good consistency with the measured stress values. In both our and their experiments, there is an uncertainty introduced by the averaging of data across the chip thickness. In addition, the results presented here are obtained from a hot chip during high-speed machining; thus, the strain can differ between the two measurements. There is also a difference in cutting geometry where Uhlmann et al. used orthogonal turning, while we use longitudinal turning resulting in differences in the chip formation. Figure 9 (b) shows the change in the Fe 110 plane spacing $\left(d_{110}\right)$ as a function of lengths cut with one tool. The plane spacing is slightly larger during the 8th length compared to the first length. The trend of $d_{110}$ vs $\gamma$ changes slightly, and the difference of $\mathrm{d}_{110}$ between the 1st and 8th length is larger at smaller $\gamma$. This indicates that the stress state changes and that the temperature in the tool-chip contact zone is higher with a worn tool.

The temperature of the chip can be estimated from the average value of the plane spacing (averaged in the range $\gamma=\left[30^{\circ}: 90^{\circ}\right]$ ) during machining. Using a coefficient of thermal expansion of 12.8 $\times 10^{-6} \mathrm{~K}^{-1}$ (Ref. 35) and a room temperature value of the plane spacing of $\mathrm{d}_{110, \mathrm{RT}}=2.025 \AA$ and $\mathrm{d}_{200, \mathrm{RT}}=1.433 \AA$, the temperature of the chip is estimated to be $670-730^{\circ} \mathrm{C}$ (for $\mathrm{d}_{110 \text {,average and }}$ $\mathrm{d}_{200 \text {,average, }}$ respectively). The mechanical strain is not known, which adds an uncertainty to this value. However, there are only small differences (within experimental error) observed between the two cutting speeds used.

Figure 9(c) shows the width of the Fe 200 and Fe 110 diffraction peaks. The peak width is largest in the chip flow direction, indicating a smaller grain size and/or larger microstrain in this direction. Brömmelhof et al. found that the size of the grains decreased in the chip flow direction due to shearing.

\section{SUMMARY}

We have successfully designed a lathe that enables industrially relevant cutting parameters and offers the stability required to study the tool insert in operando during machining using high energy $\mathrm{x}$-ray scattering. By careful selection of the substrate material, we can study the wear resistant coating and the chip on both the rake face and the flank face. We have shown that crucial parameters such as strain and temperature can be assessed during machining with this setup.

The initial results presented here indicate that as the tool becomes worn, the temperature of the chip increases. The stress state of the coating layers on the near edge flank face changes in the compressive direction during machining. The results also indicate that the stress state changes as the tool becomes worn. The average temperatures within the measurement volume at the flank face were estimated from the thermal expansion to be in the range $330-490{ }^{\circ} \mathrm{C}$ for the coatings and substrate.

\section{SUPPLEMENTARY MATERIAL}

The supplementary material contains a discussion on the importance of the correct choice of the combination of the tool (substrate and coating) and workpiece materials for designing a successful experiment with the lathe. This also motivates the choice of the tool material in the present study.

\section{ACKNOWLEDGMENTS}

The Swedish Research Council (Grant No. 2011-6505) and the German Federal Ministry of Education and Research (BMBF) (Grant No. 05K12CG1) via the Röntgen-Ångström Cluster (RÅC) Frame Program and the Swedish Government Strategic Research Area in Materials Science on Functional Materials at Linköping University (Faculty Grant No. SFO-Mat-LiU 2009-00971) are acknowledged for financial support. This study was performed in the framework of the competence center FunMat-II that is financially supported by Vinnova (Grant No. 2016-05156).

\section{REFERENCES}

${ }^{1}$ N. Norrby, M. P. Johansson, R. M’Saoubi, and M. Odén, Surf. Coat. Technol. 209, 203-207 (2012).

${ }^{2}$ A. Knutsson, M. P. Johansson, P. O. Å. Persson, L. Hultman, and M. Odén, Appl. Phys. Lett. 93, 143110 (2008).

${ }^{3}$ F. Tasnádi, I. A. Abrikosov, L. Rogström, J. Almer, M. P. Johansson, and M. Odén, Appl. Phys. Lett. 97, 231902 (2010).

${ }^{4}$ B. Alling, M. Oden, L. Hultman, and I. A. Abrikosov, Appl. Phys. Lett. 95(18), 181906 (2009).

${ }^{\mathbf{5}}$ A. Knutsson, J. Ullbrand, L. Rogström, N. Norrby, L. J. S. Johnson, L. Hultman, J. Almer, M. P. J. Jöesaar, B. Jansson, and M. Odén, J. Appl. Phys. 113, 213518 (2013).

${ }^{6}$ H. O. Gekonde and S. V. Subramanian, Surf. Coat. Technol. 149(2-3), 151-160 (2002).

${ }^{7}$ T. MacGinley and J. Monaghan, J. Mater. Process. Technol. 118(1), 293-300 (2001).

${ }^{8}$ W. Grzesik, M. Bartoszuk, and P. Nieslony, J. Mater. Process. Technol. 164-165, 1204-1211 (2005).

${ }^{9}$ L. J. Xie, J. Schmidt, C. Schmidt, and F. Biesinger, Wear 258(10), 1479-1490 (2005).

${ }^{10}$ J. Angseryd, E. Coronel, M. Elfwing, E. Olsson, and H. O. Andrén, Wear 267(5-8), 1031-1040 (2009).

${ }^{11}$ A. Flink, R. M’Saoubi, F. Giuliani, J. Sjölén, T. Larsson, P. O. Å. Persson, M. P. Johansson, and L. Hultman, Wear 266(11-12), 1237-1240 (2009).

${ }^{12}$ Y. K. Chou and C. J. Evans, Int. J. Mach. Tool. Manuf. 39(12), 1863-1881 (1999).

${ }^{13}$ H. Gürbüz, U. Şeker, and F. Kafkas, Int. J. Adv. Des. Manuf. Technol. 90(9-12), 3507-3522 (2017).

${ }^{14}$ R. M'Saoubi and H. Chandrasekaran, Int. J. Mach. Tool. Manuf. 44(2-3), 213-224 (2004).

${ }^{15}$ H. Chandrasekaran and A. Thuvander, Mach. Sci. Technol. 2(2), 355-367 (1998).

${ }^{16}$ C. Eichenseer, I. Wittmann, C. Hartig, G. A. Schneider, N. Schell, and W. Hintze, Prod. Eng. 7, 283-289 (2013).

${ }^{17}$ C. Eichenseer, C. Hartig, N. Schell, and W. Hintze, Prod. Eng. 8(4), 513-519 (2014).

${ }^{18}$ E. Uhlmann, R. Gerstenberger, S. Herter, T. Hoghé, W. Reimers, B. Camin, R. Martins, A. Schreyer, and T. Fischer, Prod. Eng. 5(1), 1-8 (2011).

${ }^{19}$ K. Brömmelhoff, S. Henze, R. Gerstenberger, T. Fischer, N. Schell, E. Uhlmann, and W. Reimers, J. Mater. Process. Technol. 213, 2211-2216 (2013).

${ }^{20}$ J. Gibmeier, D. Kiefer, R. Hofsaess, and N. Schell, Mater. Res. Proc. 6, 39-44 (2018). 
${ }^{21}$ L. Rogström, J. Ullbrand, J. Almer, L. Hultman, B. Jansson, and M. Odén, Thin Solid Films 520, 5542-5549 (2012).

${ }^{22}$ N. Norrby, L. Rogström, M. P. Johansson-Jõesaar, N. Schell, and M. Odén, Acta Mater. 73, 205-214 (2014).

${ }^{23}$ Y. H. Chen, L. Rogström, D. Ostach, N. Ghafoor, M. P. JohanssonJõesaar, N. Schell, J. Birch, and M. Odén, J. Alloys Compd. 691, 1024-1032 (2017).

${ }^{24}$ L. Rogström, N. Ghafoor, J. Schroeder, N. Schell, J. Birch, M. Ahlgren, and M. Odén, J. Appl. Phys. 118(3), 035309 (2015).

${ }^{25}$ F. Tasnádi, L. Rogström, J. Zhu, F. Wang, T. W. Hsu, H. Lind, I. A. Abrikosov, M. P. Johansson-Jõesaar, and M. Odén, Mater. Des. 150, 165-170 (2018).

${ }^{26}$ J. Almer, U. Lienert, R. L. Peng, C. Schlauer, and M. Odén, J. Appl. Phys. 94(1), 697-702 (2003).

${ }^{27}$ F. Wang, D. Holec, M. Odén, F. Mücklich, I. A. Abrikosov, and F. Tasnádi, Acta Mater. 127, 124-132 (2017).
${ }^{28}$ L. E. Toth, Transition Metal Carbides and Nitrides (Academic Press, New York, London, 1971).

${ }^{29}$ R. G. Munro, J. Am. Cer. Soc. 80(8), 1919-1928 (1997).

${ }^{30}$ J. A. Sue, Surf. Coat. Technol. 54-55, 154-159 (1992).

${ }^{31}$ L. Karlsson, A. Hörling, M. P. Johansson, L. Hultman, and G. Ramanath, Acta Mater. 50, 5103-5114 (2002).

${ }^{32}$ B. Uhrenius, Int. J. Refr. Metal. Hard Mat. 12, 121-127 (1994).

${ }^{33}$ F. Tasnádi, F. Wang, M. Odén, and I. A. Abrikosov, J. Phys.: Condens. Matter 30(13), 135901 (2018).

${ }^{34}$ B. Winkler, D. J. Wilson, S. C. Vogel, D. W. Brown, T. A. Sisneros, and V. Milman, J. Alloys Compd. 441(1), 374-380 (2007).

${ }^{35}$ M. Spittel and T. Spittel, "Thermal expansion of steel," in Metal Forming Data of Ferrous Alloys-Deformation Behaviour, Landolt-Börnstein-Group VIII Advanced Materials and Technologies Vol. 2C1 (Springer-Verlag Berlin Heidelberg, 2009), Chap. 4.5 . 